\title{
Uptake of elective laparoscopic colectomy for colon cancer in Canada from 2004/05 to 2014/15: a descriptive analysis
}

\author{
C. Marius Hoogerboord MBChB MSc, Adrian R. Levy PhD, Min Hu MA, Gordon Flowerdew DSc, \\ Geoffrey Porter MD MSc
}

\section{Abstract}

Background: Evidence from randomized controlled trials published since 2004 shows that elective laparoscopic colectomy for colon cancer improves short-term postoperative outcomes with equivalent oncologic outcomes compared to open colectomy. The objective of this study was to examine the uptake of elective laparoscopic colectomy in Canada and compare its use among Canadian provinces.

Methods: In this descriptive analysis, we identified from hospital discharge abstracts all patients in the Canadian provinces (except Quebec) who underwent elective colectomy for colon cancer between 2004/05 and 2014/15. We compared temporal changes in the proportion of patients who underwent laparoscopic colectomy or open colectomy among provinces using logistic regression.

Results: Of 63504 patients who underwent elective colectomy between 2004/05 and 2014/15, 19 691 (31.0\%) underwent laparoscopic colectomy. The annual proportion of patients who underwent laparoscopic colectomy increased from $9.2 \%$ in $2004 / 05$ to $51.5 \%$ in 2014/15 (mean annual percent increase 4.2\%). There were significant differences between provinces in the overall proportion of patients who underwent laparoscopic colectomy $(p<0.001)$, ranging from $7.6 \%$ in Newfoundland and Labrador to $36.9 \%$ in Ontario. By 2014/15, most colectomy procedures were performed laparoscopically in 3 provinces; British Columbia (60.2\%), Ontario (59.4\%) and Alberta (53.1\%). In addition to year and province, urban residence, younger age, female sex, fewer medical comorbidities, high surgeon volume, high hospital volume and right-sided tumours were significantly associated with increased likelihood of laparoscopic colectomy.

Interpretation: Although the use of laparoscopic colectomy increased rapidly between 2004/05 and 2014/15 in Canada, substantial interprovincial variation exists. Further knowledge-translation strategies are needed to ensure equal access to laparoscopic colectomy for all Canadians.

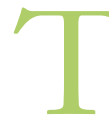

he use of elective laparoscopic colectomy for cancer in Canada is not known. Compared to open colectomy, laparoscopic colectomy reduces surgical pain and intraoperative blood loss and, subsequently, the physiologic stress response. ${ }^{1}$ By 2004 , evidence from randomized controlled trials showed that elective laparoscopic colectomy for colon cancer can be performed safely, with treatment-related mortality rates similar to those with open colectomy, while providing for accelerated inhospital recovery, reduced duration of hospital stay and reduced postoperative pain/narcotic requirements. ${ }^{2-6}$ Also, the completeness of surgical resection (as measured by the number of lymph nodes included in the specimen) and oncologic outcomes (in terms of 3- and 5-year disease-free and overall survival rates) were similar with laparoscopic and open colectomy. ${ }^{2-6}$ Since 2004 , the effectiveness and safety of laparoscopic colectomy for cancer have also been established in population-based studies. ${ }^{7-9}$

The primary objective of our study was to examine the uptake of elective laparoscopic colectomy in Canada and to compare its use among Canadian provinces (except Quebec). As secondary objectives, we 1) analyzed predictors of laparoscopic colectomy and 2) compared perioperative death and postoperative length of stay between the laparoscopic and open colectomy groups.

Competing interests: None declared.

This article has been peer reviewed.

Correspondence to: Marius Hoogerboord, hoogerboord@gmail.com CMAJ Open 2018. DOI:10.9778/cmajo.20180002 


\section{Methods}

\section{Design}

We performed a descriptive analysis of the annual proportion and uptake (mean annual percent change) of elective laparoscopic colectomy for cancer in all Canadian provinces except Quebec in the decade following publication of the seminal randomized controlled trials. ${ }^{2-6} \mathrm{We}$ analyzed the association between patient and system variables and the use of laparoscopic colectomy as well as differences in rates of in-hospital death and postoperative length of stay with laparoscopic versus open colectomy.

\section{Patients}

This study included all patients who underwent elective colectomy for colon cancer in Canada except Quebec between Apr. 1, 2004, and Mar. 31, 2015. Patients from Quebec were not included as data from that province are not reported to the Canadian Institute for Health Information. With the publication of randomized controlled trial evidence of the efficacy of elective laparoscopic colectomy for cancer, ${ }^{2-6} 2004$ is widely viewed as the tipping point in the adoption of the procedure by the surgical community..$^{10}$

\section{Data source}

We obtained our data from the Canadian Institute for Health Information Discharge Abstract Database. ${ }^{11} \mathrm{We}$ identified patients with an International Classification of Diseases and Related Health Problems, 10th revision, Canada ${ }^{12}$ code for primary diagnosis of colon cancer (C18.0-18.9 or C19) and a Canadian Classification of Health Interventions $^{13}$ procedure code for colectomy (1.NM.87, 1.NM.89, 1.NM.91 or 1.NQ.87). We differentiated open and laparoscopic colectomy using Canadian Classification of Health Interventions codes (Appendix 1, available at www. cmajopen.ca/content/6/3/E384/suppl/DC1). Our selection of diagnostic and procedure codes is consistent with codes validated by ICES. ${ }^{14}$ As of 2004, therapeutic data in the Discharge Abstract Database from all provinces were classified in a common manner according to the Canadian Classification of Health Interventions, which includes specific codes for laparoscopic colectomy. ${ }^{10}$ Before 2004, the Canadian Classification of Diagnostic, Therapeutic, and Surgical Procedures used procedure modifier codes to indicate laparoscopic colectomy, which is known to significantly underestimate its use..$^{15,16}$

\section{Inclusion criteria}

The study was limited to patients aged 18 years or more. To allow for provincial location, patients had to have a valid Canadian postal code.

\section{Exclusion criteria}

To best identify a cohort eligible for both open and laparoscopic colectomy, we excluded patients with multivisceral resection, concomitant hepatic metastasectomy or emergency presentation (peritonitis, bowel obstruction or admission via the emergency department), and those who were pregnant (Appendix 2, available at www.cmajopen.ca/content/6/3/ E384/suppl/DC1).

\section{Statistical analysis}

We compared baseline characteristics of the laparoscopic and open colectomy groups using means for continuous variables and proportions with $95 \%$ confidence intervals for discrete variables. The number and proportion of patients who underwent open or laparoscopic colectomy were reported by province and year. We conducted all analyses using Stata 14 (StataCorp).

\section{Predictors of laparoscopic colectomy}

Laparoscopy is preferred in elective colectomy; however, patient demographic and clinical factors such as age, sex, medical comorbidities, rural/urban residence, geographic location and year of surgery, and system factors such as surgeon and hospital colectomy volume may determine the surgical approach. ${ }^{17-19}$ We included these variables in a logistic regression analysis.

We defined medical comorbidities according to the Elixhauser Comorbidity Index, which has been shown to outperform other measures of comorbidity, including the Charlson Comorbidity Index, when applied to administrative data. ${ }^{20-22} \mathrm{We}$ determined rural/urban residence according to the forward sortation area based on the first 3 digits of the Canadian postal code. For average annual hospital and surgeon volumes, we calculated the average number of colectomy procedures for years in which at least 1 colectomy procedure was performed for each surgeon and hospital. We categorized the average volumes into quartiles and then dichotomized them into high ( $\geq 75$ th percentile) and low (< 75 th percentile), respectively. Therefore, a highvolume surgeon would, on average, perform more than 7 colectomy procedures per year, and at least 37 colectomy procedures would be performed annually in a high-volume hospital. We assessed the association between laparoscopic colectomy and each predictor variable using univariate logistic regression. Variables with a $p$ value $\leq 0.2$ were included in an initial multivariate logistic regression model. The final multivariate model included all variables with a $p$ value $<0.05$. Associations were reported as odds ratio and $95 \%$ confidence interval for univariate analyses and as adjusted odds ratio and $95 \%$ confidence interval for multivariate analyses.

To assess the effects of clustering, we compared the mean proportion of provincial laparoscopic colectomy procedures per patient to that of surgeons and the mean proportion of provincial laparoscopic colectomy procedures of surgeons to that of institutions using a 1 -tailed paired $t$ test.

\section{Postoperative outcomes}

We compared mean postoperative length of stay (defined as number of days from the day of surgery up to and including the day of discharge) and rates of in-hospital death between the laparoscopic colectomy and open colectomy groups using 
the Student $t$ test and the $\chi^{2}$ test, respectively. Patients who died in hospital were excluded from analysis of length of stay.

\section{Ethics approval}

This study was approved by the Research Ethics Board of the Nova Scotia Health Authority, Halifax.

\section{Results}

Across the 9 provinces, the Discharge Abstract Database identified 105302 records of patients who underwent colectomy for colon carcinoma between 2004/05 and 2014/15. Applying the exclusion criteria yielded 63504 records (Figure 1); 19691 patients $(31.0 \%)$ underwent laparoscopic colectomy, and $43813(69.0 \%)$ underwent open colectomy. Patient and system characteristics of the 2 groups are presented in Table 1 and Appendix 3 (available at www.cmajopen.ca/content/6/3/ E384/suppl/DC1). Although the differences in demographic, clinical and system factors were statistically significant owing to the large cohort size, some of the differences were of modest clinical significance.

\section{Use and uptake of elective laparoscopic colectomy}

The overall use of elective laparoscopic colectomy and open colectomy for colon cancer in Canada from 2004/05 to 2014/15 is depicted in Figure 2. Over that period, the number of patients who underwent colectomy for colon cancer annually increased from 5601 to 5976 . The proportion of patients who underwent laparoscopic colectomy increased from $9.2 \%$ in $2004 / 05$ to $51.5 \%$ in $2014 / 15$. The increase in laparoscopic colectomy use over time appeared linear, with an average annual percent change of $4.2 \%$.

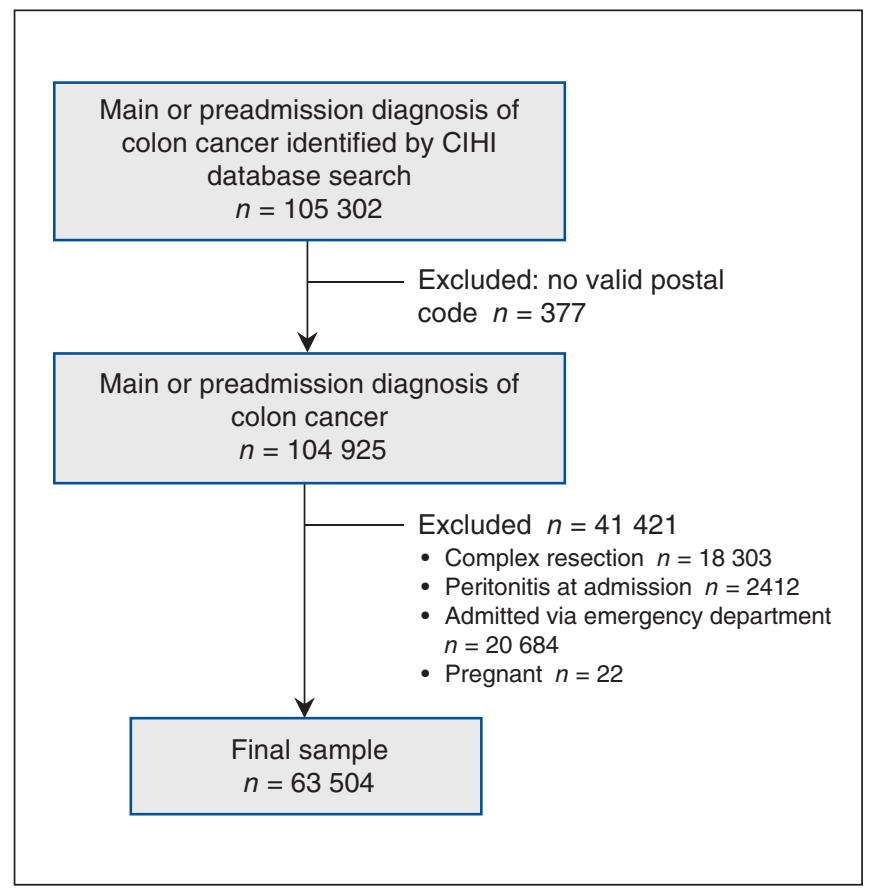

Figure 1: Flow diagram showing cohort selection. Note: $\mathrm{CIHI}=$ Canadian Institute for Health Information.
Table 1: Patient demographic and clinical characteristics and system characteristics for patients who underwent elective laparoscopic or open colectomy for colon cancer between 2004/05 and 2014/15 in Canada (excluding Quebec)

\begin{tabular}{|lcc|}
\hline & \multicolumn{2}{c}{$\begin{array}{c}\text { Group; no. (\%) of patients* } \\
(95 \% \mathrm{Cl})\end{array}$} \\
\cline { 2 - 3 } Variable & $\begin{array}{c}\text { Laparoscopic } \\
n=19691\end{array}$ & $\begin{array}{c}\text { Open } \\
n=43813\end{array}$ \\
\hline Age, yr, mean \pm SD & $69 \pm 12$ & $70 \pm 12$ \\
& $(68.8-69.1)$ & $(69.8-70.1)$ \\
\hline Sex & & \\
\hline Male & & $24158(55.1)$ \\
& $10416(52.9)$ & $(54.7-55.6)$ \\
\hline Female & $(52.2-53.6)$ & $19655(44.9)$ \\
& $9275(47.1)$ & $(44.4-45.3)$ \\
\end{tabular}

Elixhauser

Comorbidity Index score

\begin{tabular}{ccc}
0 & $\begin{array}{c}12854(65.3) \\
(65.0-66.0)\end{array}$ & $\begin{array}{c}28176(64.3) \\
(64.0-65.0)\end{array}$ \\
\hline $1-3$ & $6714(34.1)$ & $15297(34.9)$ \\
& $(33.4-34.8)$ & $(34.5-35.4)$ \\
$>3$ & $123(0.6)$ & $340(0.8)$ \\
& $(0.5-0.8)$ & $(0.7-0.9)$ \\
\hline
\end{tabular}

\begin{tabular}{|ccc|}
\hline Residence & & \\
\hline Rural & $3253(16.5)$ & $10560(24.1)$ \\
& $(16.0-17.1)$ & $(23.7-24.5)$ \\
\hline Urban & $16438(83.5)$ & $33253(75.9)$ \\
& $(82.9-83.9)$ & $(75.5-76.3)$
\end{tabular}

\begin{tabular}{|ccc|}
\hline Surgeon volume & & \\
\hline Low (1-7) & $\begin{array}{c}5771(29.3) \\
(28.7-29.9)\end{array}$ & $\begin{array}{c}17681(40.4) \\
(39.9-40.8)\end{array}$ \\
\hline High (8-37) & $\begin{array}{c}26132(59.6) \\
(70.1-71.3)\end{array}$ & $(59.2-60.1)$ \\
\hline Hospital volume & & \\
\hline Low (1-36) & $5301(26.9)$ & $20100(45.9)$ \\
& $(26.3-27.5)$ & $(45.5-46.4)$ \\
\hline High (37-102) & $14390(73.1)$ & $23713(54.1)$ \\
& $(72.5-73.7)$ & $(53.7-54.6)$ \\
\hline Resection type & & $19902(45.4)$ \\
\hline Right & $10004(50.8)$ & $(44.9-45.9)$ \\
hemicolectomy & $(50.1-51.5)$ & $12200(27.8)$ \\
\hline Left hemicolectomy & $5809(29.5)$ & $(27.4-28.3)$ \\
& $(28.9-30.1)$ & $8403(19.2)$ \\
\hline Anterior resection & $2706(13.7)$ & $(18.8-19.6)$ \\
& $(13.3-14.2)$ & $3308(7.6)$ \\
& $1172(6.0)$ & $(7.3-7.8)$ \\
\hline Other & $(5.6-6.3)$ & \\
& & \\
\hline $\begin{array}{l}\text { Note: Cl = confidence interval, SD }=\text { standard deviation. } \\
\text { *Except where noted otherwise. }\end{array}$ & \\
\hline
\end{tabular}




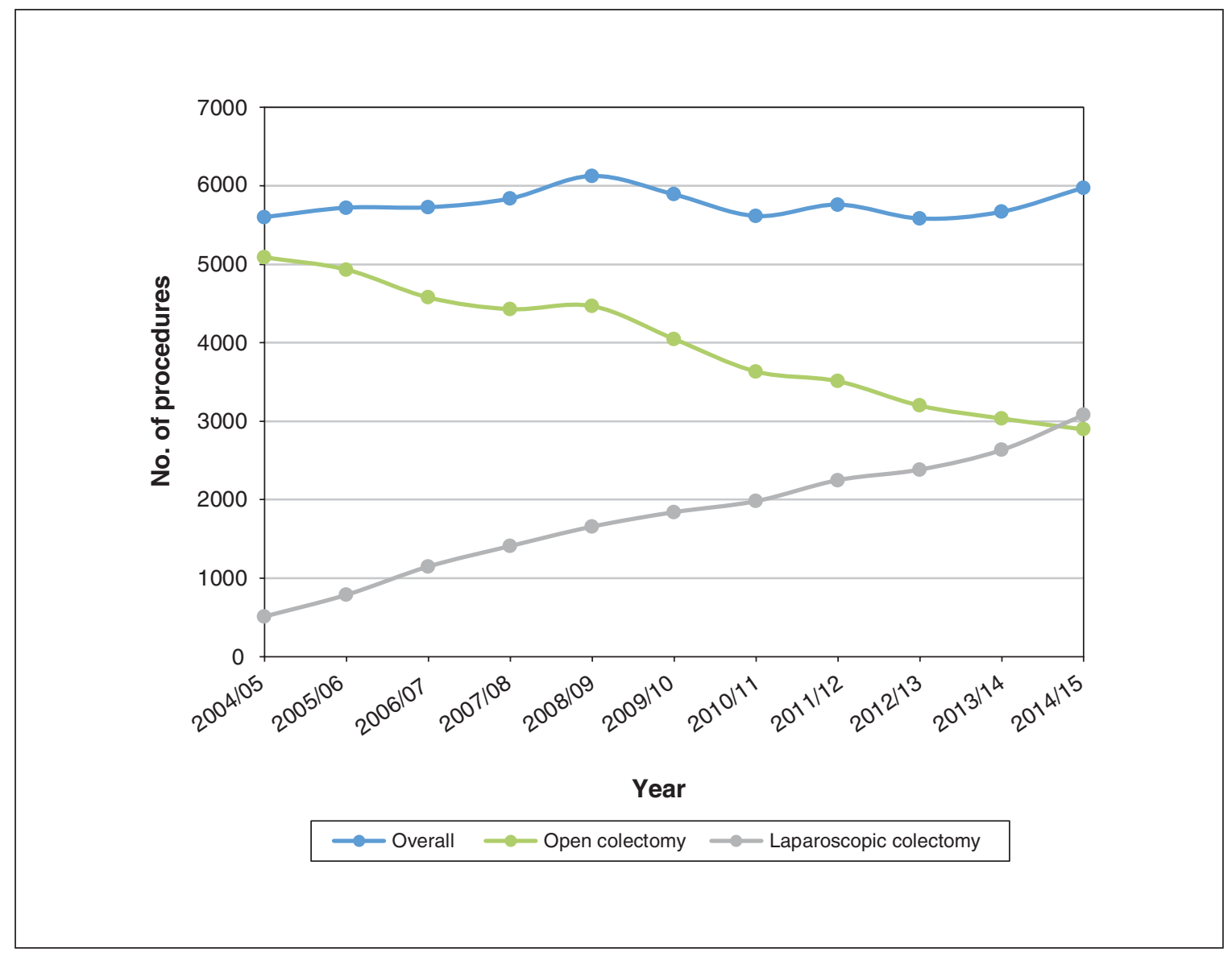

Figure 2: Number of overall, open and elective laparoscopic colectomy procedures for colon cancer in Canadian provinces except Quebec, 2004/05 to 2014/15.

The annual proportional use of laparoscopic colectomy by province is presented in Figure 3. Newfoundland and Labrador had the lowest uptake of the procedure, with a mean annual percent change of $0.6 \%$ per year, such that only $11.2 \%$ of patients in the province were treated laparoscopically in 2014/15. The greatest increase in the use of laparoscopic colectomy was observed in Prince Edward Island, where the proportion increased from $1.9 \%$ in $2012 / 13$ to $43.1 \%$ in 2014/15. An overall average annual percent change of $4.7 \%$ was seen in Ontario, with a particularly steep increase of $9.5 \%$ between 2005/06 and 2006/07. In 2014/15, 59.4\% of patients with colon cancer in Ontario underwent laparoscopic colectomy. The highest average annual percent change, $5.3 \%$, was observed in British Columbia, with $60.2 \%$ of patients undergoing laparoscopic colectomy in 2014/15. By 2014/15, the majority of patients $(53.1 \%)$ with colon cancer in Alberta underwent laparoscopic colectomy.

\section{Predictors of use of laparoscopic colectomy}

Factors associated with the use of laparoscopic colectomy are presented in Table 2. On univariate analysis, laparoscopic colectomy was more commonly used in urban patients, those treated at high-volume hospitals and by high-volume surgeons, and those who underwent right hemicolectomy. All variables remained statistically significant and were included in the final regression model. Multivariate analyses showed year of surgery to be the strongest predictor of laparoscopic colectomy: patients were 9.3 times more likely to undergo laparoscopic colectomy in 2014/15 than in 2004/05. Adjusted provincial differences were also substantial, with patients in Newfoundland and Labrador being $86.0 \%$ less likely to undergo laparoscopic colectomy than those in Ontario. Urban residence, younger age, high surgeon volume and high hospital volume were significantly associated with increased likelihood of laparoscopic colectomy, whereas male sex, medical comorbidities, age greater than 80 years, left-sided resection and multisegment resection were associated with lower likelihood of the procedure.

\section{Assessment of clustering}

The mean proportion of laparoscopic colectomy procedures per surgeon was lower than that per patient $(0.26 \mathrm{v} .0 .31, p=$ $0.02)$ and was lower per institution than per surgeon $(0.23 \mathrm{v}$. $0.26, p=0.02)$. This reflects a clustering of the procedure within physicians and additional clustering within institutions, with more procedures being performed by high-volume surgeons and in high-volume hospitals (Appendix 4, available at www.cmajopen.ca/content/6/3/E384/supp1/DC1). 


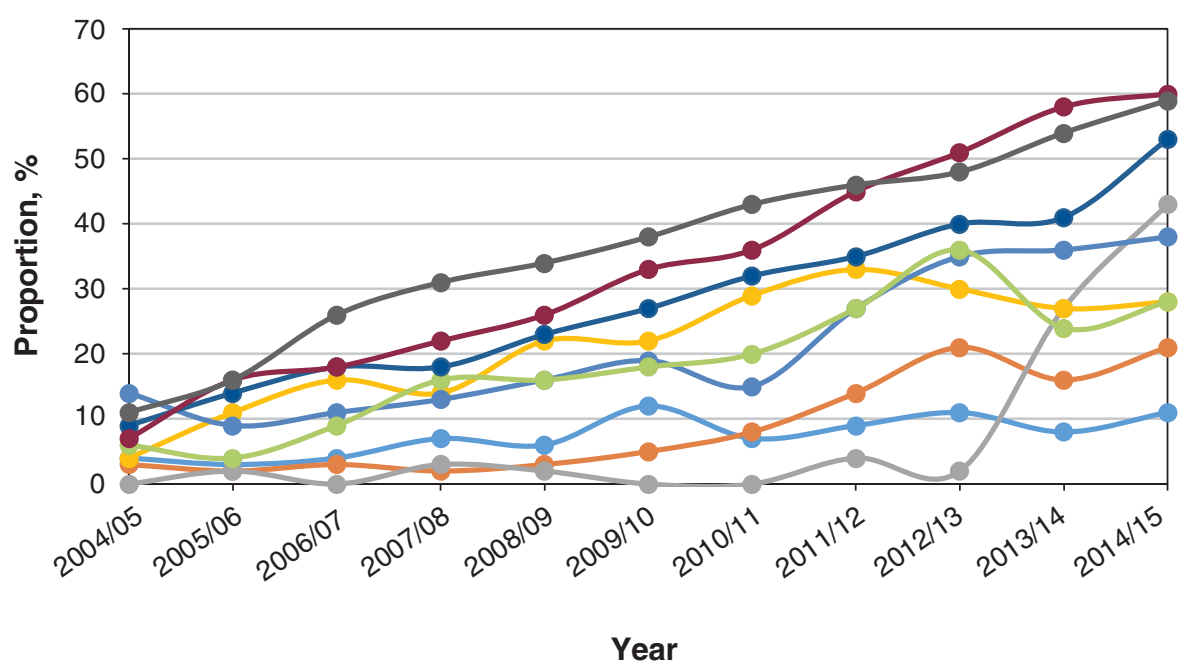

\begin{tabular}{|c|c|c|}
\hline — British Columbia & $\longrightarrow$ Alberta & — Saskatchewan \\
\hline- Manitoba & $\longrightarrow$ Ontario & - New Brunswick \\
\hline - Nova Scotia & _ Prince Edward Island & _ Newfoundland and Labrador \\
\hline
\end{tabular}

Figure 3: Annual proportion of elective laparoscopic colectomy procedures by province, 2004/05 to 2014/15.

\section{Early postoperative outcomes}

The in-hospital mortality rate was lower among patients who underwent laparoscopic colectomy than among those who underwent open colectomy ( $0.8 \%$ v. $2.0 \%, p<0.001)$. Overall, length of stay was shorter by an average of 2.94 days (standard deviation $7.5 \mathrm{~d}$ ) for patients who underwent laparoscopic colectomy than for those who underwent open colectomy $(p<0.001)$.

\section{Interpretation}

We found that the overall proportion of laparoscopic colectomy procedures increased over time in 9 Canadian provinces, from $9.2 \%$ in $2004 / 05$ to $51.5 \%$ in $2014 / 15$. We observed significant interprovincial variation in the annual use and uptake of the procedure. By 2014/15, rates of use ranged from $60 \%$ in British Columbia to $11 \%$ in Newfoundland and Labrador. Compared to patients who underwent open colectomy, patients who underwent laparoscopic colectomy had a lower in-hospital mortality rate and a shorter postoperative length of stay. Factors that increased the likelihood of laparoscopic colectomy included later year of study, younger age, fewer medical comorbidities, urban residence, right hemicolectomy, high surgeon volume and high hospital volume. It is therefore not surprising that provinces with older populations and higher rural/urban ratios had lower uptake of laparoscopic colectomy.
The magnitude of the increase in the use of laparoscopic colectomy observed in Canada is comparable to that reported in the United Kingdom but lower than in South Korea, the Netherlands and the United States. ${ }^{23-26}$ Significant regional variation in laparoscopic colectomy rates have been described, for example, ranging from $0 \%$ to $96 \%$ among hospitals in the Netherlands and from $0 \%$ to $67 \%$ across hospital referral regions in the US. ${ }^{25,27}$ Surgeon preference is an important determinant of variation and is guided primarily by training and experience, as well as institutional culture. ${ }^{28}$ Financial incentives for laparoscopic colectomy may also influence surgeon behaviour. The introduction of a $25 \%$ fee premium for laparoscopic colectomy in Ontario may have been a factor in the increased uptake observed between 2005/06 and 2006/07. ${ }^{8}$ However, similar laparoscopic fee codes introduced in British Columbia and Nova Scotia in 2011 did not have the same effect.

Randomized controlled trials showed a similar in-hospital mortality rate, enhanced postoperative recovery with shorter postoperative length of stay and equivalent oncologic outcomes of elective laparoscopic colectomy and open colectomy. ${ }^{2-5}$ These were subsequently confirmed by population-based studies, although some investigators reported lower inhospital mortality with laparoscopic colectomy..$^{7,8,29-31}$ Our pan-Canadian data substantiate shorter length of hospital stay and a decreased in-hospital mortality rate for laparoscopic colectomy. 


\begin{tabular}{|c|c|c|}
\hline \multirow[b]{2}{*}{ Variable } & \multicolumn{2}{|c|}{$\mathrm{OR}^{\star}(95 \% \mathrm{Cl})$} \\
\hline & Univariate & Multivariate \\
\hline $\begin{array}{l}\text { Year }(2014 / 15 \text { relative to } \\
2004 / 05)\end{array}$ & 7.55 (7.12-8.00) & $9.31(8.60-10.09)$ \\
\hline Female sex (reference) & 1.00 & 1.00 \\
\hline Male sex & $0.92(0.88-0.95)$ & $0.94(0.90-0.98)$ \\
\hline \multicolumn{3}{|l|}{ Age, yr } \\
\hline 66-80 (reference) & 1.00 & 1.00 \\
\hline $18-50$ & $1.19(1.11-1.28)$ & $1.15(1.07-1.24)$ \\
\hline $51-65$ & $1.11(1.06-1.15)$ & $1.14(1.09-1.19)$ \\
\hline$>80$ & $0.93(0.89-0.98)$ & $0.87(0.83-0.92)$ \\
\hline \multicolumn{3}{|l|}{ Province } \\
\hline Ontario (reference) & 1.00 & 1.00 \\
\hline $\begin{array}{l}\text { Newfoundland and } \\
\text { Labrador }\end{array}$ & $0.12(0.10-0.14)$ & $0.14(0.12-0.16)$ \\
\hline New Brunswick & $0.15(0.13-0.17)$ & $0.16(0.14-0.19)$ \\
\hline Prince Edward Island & $0.14(0.11-0.20)$ & $0.23(0.17-0.32)$ \\
\hline Manitoba & $0.36(0.33-0.39)$ & $0.39(0.36-0.43)$ \\
\hline Saskatchewan & $0.42(0.38-0.46)$ & $0.54(0.49-0.60)$ \\
\hline Nova Scotia & $0.44(0.40-0.48)$ & $0.53(0.48-0.59)$ \\
\hline Alberta & $0.64(0.60-0.67)$ & $0.57(0.53-0.60)$ \\
\hline British Columbia & $0.86(0.82-0.90)$ & $0.89(0.85-0.93)$ \\
\hline \multicolumn{3}{|l|}{ Residence } \\
\hline Rural (reference) & 1.00 & 1.00 \\
\hline Urban & $1.68(1.61-1.76)$ & $1.24(1.18-1.30)$ \\
\hline
\end{tabular}

\section{Elixhauser Comorbidity}

Index score

\begin{tabular}{|ccc|}
\hline 0 (reference) & 1.00 & 1.00 \\
\hline $1-3$ & $0.88(0.85-0.92)$ & $0.90(0.87-0.94)$ \\
\hline $4-8$ & $0.76(0.61-0.94)$ & $0.79(0.63-0.98)$ \\
\hline Hospital volume & 1.0 & 1.00 \\
\hline Low (reference) & $2.44(2.35-2.54)$ & $2.04(1.96-2.13)$ \\
\hline High & & \\
\hline Surgeon volume & 1.00 & 1.00 \\
\hline Low (reference) & $1.65(1.59-1.71)$ & $1.29(1.24-1.35)$ \\
\hline High & & \\
\hline Resection type & 1.00 & 1.00 \\
\hline Right (reference) & $0.97(0.93-1.01)$ & $0.91(0.87-0.95)$ \\
\hline Left & $0.75(0.70-0.81)$ & $0.58(0.55-0.62)$ \\
\hline Anterior & $0.66(0.63-0.70)$ & $0.71(0.66-0.76)$ \\
\hline Other & & \\
\hline
\end{tabular}

Note: $\mathrm{Cl}=$ confidence interval, $\mathrm{OR}=$ odds ratio.

*Adjusted for all other variables included in the model in multivariate analysis.

\section{Limitations}

There are several limitations to our study. The observed differences in mortality and length of stay outcomes, even after we controlled for modest differences in baseline characteristics of the open and laparoscopic groups, may be at least partially explained by unmeasured factors contributing to a selection bias. Several clinical variables (e.g., body mass index, tumour stage, local recurrence v. primary tumour, prior abdominal operation) were not available in the Discharge Abstract Database, and thus we were unable to examine their association with laparoscopic colectomy use. In addition, we were not able to distinguish between the various types of laparoscopic colectomy (e.g., completed laparoscopic, laparoscopic assisted, laparoscopic converted to open); therefore, laparoscopic colectomy in this study should be interpreted as a procedure that was at least initiated laparoscopically. We had no baseline data on years of experience and practice preferences of the surgeon cohort before 2004/05 and were also not able to distinguish fellowshiptrained subspecialist surgeons and how these factors affected interprovincial variation. We did not have access to pathology reports and therefore could not verify the oncologic completeness of resection. Finally, the lack of inclusion of Quebec may limit the generalizability of the study findings to that province.

\section{Conclusion}

Although rates of elective laparoscopic colectomy for cancer increased significantly in Canada in the decade following the publication of seminal randomized trials, there is still room for improvement. Substantial interprovincial variation in use of laparoscopic colectomy exists, with lowest use in provinces with smaller, older and more rural populations. Further knowledgetranslation strategies are needed to ensure equal access to the benefits of laparoscopic colectomy for all Canadians.

\section{References}

1. Kehlet H, Wilmore DW. Multimodal strategies to improve surgical outcome Am 7 Surg 2002;183:630-41.

2. Laparoscopically assisted colectomy is as safe and effective as open colectomy in people with colon cancer. Abstracted from: Nelson H, Sargent D, Wieand HS, et al; for the Clinical Outcomes of Surgical Therapy Study Group. A comparison of laparoscopically assisted and open colectomy for colon cancer. $N$ Engl 7 Med 2004; 350: 2050-2059. Cancer Treat Rev 2004;30:707-9.

3. Veldkamp R, Kuhry E, Hop WC, et al. COlon cancer Laparoscopic or Open Resection Study Group (COLOR). Laparoscopic surgery versus open surgery for colon cancer: short-term outcomes of a randomised trial. Lancet Oncol 2005; 6:477-84.

4. Guillou PJ, Quirke P, Thorpe H, et al. MRC CLASICC trial group. Short-term endpoints of conventional versus laparoscopic-assisted surgery in patients with colorectal cancer (MRC CLASICC trial): multicentre, randomised controlled trial. Lancet 2005;365:1718-26.

5. Lacy AM, García-Valdecasas JC, Delgado S, et al. Laparoscopy-assisted colectomy versus open colectomy for treatment of non-metastatic colon cancer: a randomised trial. Lancet 2002;359:2224-9.

6. Schwenk W, Haase O, Neudecker J, et al. Short term benefits for laparoscopic colorectal resection. Cochrane Database Syst Rev 2005;(3):CD003145.

7. Aslani N, Lobo-Prabhu K, Heidary B, et al. Outcomes of laparoscopic colon cancer surgery in a population-based cohort in British Columbia: Are they as good as the clinical trials? Am 7 Surg 2012;204:411-5.

8. Simunovic M, Baxter NN, Sutradhar R, et al. Uptake and patient outcomes of laparoscopic colon and rectal cancer surgery in a publicly funded system and following financial incentives. Ann Surg Oncol 2013;20:3740-6.

9. Zheng Z, Jemal A, Lin CC, et al. Comparative effectiveness of laparoscopy vs open colectomy among nonmetastatic colon cancer patients: an analysis using the National Cancer Data Base. 7 Natl Cancer Inst 2015;107:dju491.

10. Senagore AJ. Adoption of laparoscopic colorectal surgery: it was quite a journey. Clin Colon Rectal Surg 2015;28:131-4. 
11. Discharge Abstract Database metadata (DAD). Ottawa: Canadian Institute for Health Information; 2017. Available: https://www.cihi.ca/en/discharge -abstract-database-metadata (accessed 2017 Dec. 3).

12. International Statistical Classification of Diseases and Related Health Problems, 10th revision. Ottawa: Canadian Institute for Health Information (CIHI); 2009. Available: https://www.cihi.ca/en/icd_10_ca_vol1_2009_en.pdf (accessed 2017 Dec. 3).

13. Canadian Classification of Health Interventions: volume three - tabular list. Ottawa: Canadian Institute for Health Information (CIHI); 2012. Available: https://www.cihi.ca/en/cci_volume_three_2012_en.pdf (accessed 2017 Dec. 3).

14. Juurlink D, Preyra C, Croxford R, et al. Canadian Institute for Health Information Discharge Abstract Database: a validation study. Toronto: Institute for Clinical Evaluative Sciences; 2006. Available: https://www.ices.on.ca/flip-publication/ canadian-istitute-for-health-information-discharge/files/assets/basic-html/index. html\#3 (accessed 2018 Mar. 27).

15. Langenfeld SJ, Thompson JS, Oleynikov D. Laparoscopic colon resection: Is it being utilized? Adv Surg 2013;47:29-43.

16. Sticca RP, Alberts SR, Mahoney MR, et al. Current use and surgical efficacy of laparoscopic colectomy in colon cancer. 7 Am Coll Surg 2013;217:56-62, discussion 62-3.

17. Vogel JD, Eskicioglu C, Weiser MR, et al. The American Society of Colon and Rectal Surgeons clinical practice guidelines for the treatment of colon cancer. Dis Colon Rectum 2017;60:999-1017.

18. Zerey M, Hawver LM, Awad Z, et al.; Members of the SAGES Guidelines Committee. SAGES evidence-based guidelines for the laparoscopic resection of curable colon and rectal cancer. Surg Endosc 2013;27:1-10.

19. Xynos E, Gouvas N, Triantopoulou C, et al.; the Executive Team on behalf of the Hellenic Society of Medical Oncology (HeSMO). Clinical practice guidelines for the surgical management of colon cancer: a consensus statement of the Hellenic and Cypriot Colorectal Cancer Study Group by the HeSMO. Ann Gastroenterol 2016;29:3-17.

20. Elixhauser A, Steiner C, Harris DR, et al. Comorbidity measures for use with administrative data. Med Care 1998;36:8-27.

21. Southern DA, Quan H, Ghali WA. Comparison of the Elixhauser and Charlson/Deyo methods of comorbidity measurement in administrative data. Med Care 2004:42:355-60.

22. Sharabiani MT, Aylin P, Bottle A. Systematic review of comorbidity indices for administrative data. Med Care 2012;50:1109-18.

23. National Bowel Cancer Audit Report — 2015. Leeds (UK): NHS Digital; 2015. Available: https://files.digital.nhs.uk/publicationimport/pub19xxx/ pub19500/nati-clin-audi-bowe-canc-2015.pdf (accessed 2017 Oct. 23).

24. Park SJ, Lee KY, Lee S. Laparoscopic surgery for colorectal cancer in Korea: nationwide data from 2008-2013. F Minim Invasive Surg 2015;18:39-43.

25. Kolfschoten NE, van Leersum NJ, Gooiker GA, et al. Successful and safe introduction of laparoscopic colorectal cancer surgery in Dutch hospitals. Ann Surg 2013;257:916-21.
26. Moghadamyeghaneh Z, Carmichael JC, Mills S, et al. Variations in laparoscopic colectomy utilization in the United States. Dis Colon Rectum 2015;58: 950-6.

27. Reames BN, Sheetz KH, Waits SA, et al. Geographic variation in use of laparoscopic colectomy for colon cancer. 7 Clin Oncol 2014;32:3667-72.

28. Westert GP, Groenewegen PP. Medical practice variations: changing the theoretical approach. Scand f Public Health 1999;27:173-80.

29. Cone MM, Herzig DO, Diggs BS, et al. Dramatic decreases in mortality from laparoscopic colon resections based on data from the Nationwide Inpatient Sample. Arch Surg 2011;146:594-9.

30. Babaei M, Balavarca Y, Jansen L, et al. Minimally invasive colorectal cancer surgery in Europe: implementation and outcomes. Medicine (Baltimore) 2016;95: e3812.

31. Dobbins TA, Young JM, Solomon MJ. Uptake and outcomes of laparoscopically assisted resection for colon and rectal cancer in Australia: a population-based study. Dis Colon Rectum 2014;57:415-22.

Affiliations: Division of General Surgery (Hoogerboord, Porter), Department of Surgery, Dalhousie University; Department of Community Health and Epidemiology (Hoogerboord, Levy, Flowerdew, Porter), Dalhousie University; Department of Economics (Hu), Dalhousie University, Halifax, NS

Contributors: Geoffrey Porter oversaw all aspects of the project. Geoffrey Porter and Marius Hoogerboord conceived and designed the study. Marius Hoogerboord acquired the data. Marius Hoogerboord, Min $\mathrm{Hu}$, Gordon Flowerdew and Geoffrey Porter analyzed and interpreted the data. Adrian Levy, Min Hu, Gordon Flowerdew and Geoffrey Porter drafted the manuscript, and Marius Hoogerboord and Geoffrey Porter revised it critically for important intellectual content. All of the authors gave final approval of the version to be published and agreed to be accountable for all aspects of the work.

Disclaimer: This study was supported by ICES, which is funded by an annual grant from the Ontario Ministry of Health and Long-Term Care (MOHLTC). The opinions, results and conclusions reported in this article are those of the authors and are independent from the funding sources. No endorsement by ICES or the MOHLTC is intended or should be inferred.

Supplemental information: For reviewer comments and the original submission of this manuscript, please see www.cmajopen.ca/content/6/3/ E384/suppl/DC1. 